\title{
Complicated Working Time Arrangements: A construction industry case study
}

\section{Keith Townsend $(\mathrm{PhD})^{1}$, Helen Lingard $(\mathrm{PhD})^{2}$, Lisa Bradley $(\mathrm{PhD})^{3}$, and Kerry Brown $(\mathbf{P h D})^{4}$}

\section{Abstract}

This paper extends the understanding of working time changes and work-life balance through analysing a case study where a reduction in working hours designed to assist the workforce balance their work and non-work life was implemented. An alliance project in the Australian construction industry was established initially with a five-day working week, a departure from the industry standard six-day week. However, a range of factors complicated the success of this initiative and the industry standard six-day working week was re-instated for the project.

We argue that this case is valuable in determining the complex mix of influences that work against a wholesale or straightforward adoption of working time adjustments and work-life balance practices. It is concluded that while the prevailing workplace culture is considered an important factor in the determination of working time, structural and workplace principles and practices may also be critical in working to secure to successful introduction of working time reduction and work-life balance initiatives in the construction industry in the future.

\footnotetext{
${ }^{1}$ Senior Research Fellow in the Centre for Work, Organisation and Wellbeing, Griffith University, Nathan, Queensland, Australia, 4111.

${ }^{2}$ Professor of Construction in the School of Property Construction and Property Management at RMIT, Melbourne, Australia, 3000.

${ }^{3}$ Head of School and Professor of Management in the School of Management, Queensland University of Technology, Brisbane, Australia, 4000.

${ }^{4}$ Professor (Mulpha Chair) in the School of Tourism and Hospitality Management, Tweed Heads, Australia, 2485.
} 


\section{Introduction}

Throughout recent years there has been a significant development of academic, media and political attention focussed on long working hours and the negative impacts on work life balance (WLB). Viewed in total, this evidence overwhelmingly suggests that extended working hours and the difficulty of balancing home and work are problematic for many employees (Clark 2001; Dawson, McCulloch \& Baker 2001; Pocock 2001, 2003; Brett and Stroh 2003; Townsend et al. 2003). However, much of this research has been performed in workplaces that are stable, and have consistent patterns of work, with the object of analysis often professional occupations and the policies available to these people (Chang, Mcdonald and Burton, 2010). Organisations within the construction industry are complex, often changing in structure between major jobs, have geographic mobility, are faced with sectoral and economic instability, and traditionally have long working hours and employ mostly men. As such, it is a sector which is not often the focus of work life balance research.

While problems of job dissatisfaction, increased turnover intention, lack of general well-being, substance abuse and psychological and psychiatric problems have been found to be caused by imbalances of work and non-work life (Allen et al. 2000; Netemeyer, Boles \& McMurrian 1996; Boyar et al.2003), we know that long and unsocial working hours are two elements of working time arrangements that have the potential to impede good WLB. As a sub-sector of the work life balance debate, the area of flexible work time practices have received research attention as contributing to improving work-life balance. However the adjustment of working time arrangements to deliver better work options for employees has been difficult to achieve. 
This paper presents and analysis of the complexities for managers involved in seeking better WLB options for employees, while attempting to maintain overall commitment to project goals, including timelines and budgets. This case study was an 'alliance' of public and private sector organisations charged with the construction of a large, government funded infrastructure development in Queensland, Australia.

Australia does not have statutory limits on working hours and previous research indicates that Australian workers do not have a great deal of control over their working time (Peetz, Townsend, Russell, Houghton, Fox and Allan, 2003). Typically, blue collar workers in the construction industry rank as those employees working the longest average working hours (van Wanrooy, 2007). Long work hours are considered to be weekly hours above 40 hours per week, and very long hours constitute weekly hours above 49 (Campbell, 2005). In light of this, employees within the construction industry are working very long hours with site-based employees averaging around 63 hours per week (Lingard and Rowlinson 2005).In our case study, the alliance management group acknowledged that work and life balance (WLB) was problematic within the industry, reflecting on the 'industry-standard' six day working week. As part of their project management strategy, the management group decided to implement a five-day working week as a work-life balance initiative. Internally, many employees were sceptical but willing to experiment with the five-day system. However, a combination of internal and external forces meant the five-day working week was not sustainable. Despite the failure of the transition to a five-day week for the site, the management group persevered and implemented a more restricted version of the five-day week for the workforce.

The remainder of this article is structured as follows. Firstly, we provide a review of the relevant WLB and working time literature. This review is focussed on 
two main areas of concern, the effect of long hours on the working environment and the workers and the issues of working time with specific reference to the construction industry. This is followed by an explanation of the research methodology. The third section describes the alliance project and explores the reasons why the five-day working week was not sustainable in this case. This section also details some alternative rostering arrangements that the management group implemented to compensate for the failed five-day week. Finally, the fourth section of this paper analyses employee perceptions of their WLB at this worksite and possibilities for future reform.

We argue that this case is valuable in determining that there can be a complex mix of influences that work against a wholesale or straightforward adoption of altered working time arrangements and practices to improve the work-life balance experiences of employees. It is concluded that while the prevailing workplace culture is considered an important factor in the adoption of work-life balance initiatives, structural and workplace principles and practices may also be very critical in working to secure the successful introduction of work-life balance initiatives. Throughout this analysis we will explore the structural and workplaces factor as they influence decision-making in the workplace.

\section{Working Time and Work Life Balance in the Construction Industry}

There is a range of research that suggests that WLB is not just about the amount of time spent in work and non-work activities (Greenhaus et al 2003). This desired balance will vary between individual people - not everyone wants the same levels of work and non-work activities. Nevertheless, the number of hours an employee works is a centrally important part of the WLB rhetoric. Indeed, the length of shifts, working days and weeks and hours worked over a year are all areas of previously published 
research. Kodz, Davis, Lain, Sheppard et al. (2003) report that, in the United Kingdom, workers' satisfaction with life decreased with the number of hours worked. Following a multi-national study of workers in the United States, the United Kingdom and Hong Kong, Wharton \& Blair-Loy (2006) report that long hours (especially when combined with tight deadlines) increase workers' concerns that their work negatively impacts upon family life - a clear inversely proportionate relationship between the number of hours worked and WLB. The Relationships Forum Australia (RFA) has defined 'long working hours' (i.e. those at which family relationships are negatively affected) as working 45 or more hours per week (Shepanski \& Diamond, 2007).

Australia is one of a small number of industrialised countries where employee working hours have increased in the last fifteen years (Campbell 2002). Often, employees have limited control over the hours that they are working (Peetz et al. 2003). These increased hours and diminished control have increased significantly and this can have negative implications for health and safety at work (Dawson, McCulloch \& Baker 2001). More broadly, excessive working hours have been suggested to have a negative impact on the coherence of social relations within families and communities (Peetz et al, 2003; Pocock, 2003; Pocock \& Clarke 2005; Townsend et al 2003).

Based on a comparison of nine OECD countries, Jacobs and Gerson (2000: 93-95) found that Australia had the highest proportion of the workforce working more than 50 hours per week. The problem of extended working hours was the catalyst for the Australian Council of Trade Unions (ACTU) to pursue its 2001 'reasonable hours' test case in the Australian Industrial Relations Commission (AIRC). This test case seems to have had limited impact in the workplace because in 2004 almost one and a 
half million Australian employees still worked more than 50 hours a week (Campbell 2005).

Construction industry workers in Australia are expected to work non-standard work schedules, including regular weekend work. The construction industry has a demanding work environment, with longer than average working hours (Lingard \& Francis 2004). Most construction sites operate on a six-day week basis, with salaried and waged staff often working very long hours. A survey of construction industry employees revealed that the average number of hours worked each week was 62.5 among site-based project staff (Lingard \& Francis 2004). Goldenhair et al (2003) recognise that excessive overtime leads to a significantly higher risk of adverse health and safety outcomes amongst construction industry workers in the United States.

Employment available within construction industry is cyclical around macro issues such as periods of economic growth and downturn, but also on a seasonal and daily basis due to weather conditions. That is to say, whilst projects managers can plan around known high rainfall seasons, inclement weather is an uncontrollable factor. What these known concerns mean is that many wage earning construction workers typically work paid overtime to create a 'financial cushion' (Bluestone and Rose 1998) to sustain their families through periods of no work. Paid overtime is not, however, readily available to salaried construction industry employees. The link between systems of remuneration and working time is crucial in the complicated mix of factors within this case, and indeed within the construction industry.

The employees who work in our case study project engage in long hours of work on the basis of extra hours each day in overtime. Overtime is usually manifest in one of two forms: paid and unpaid overtime. Campbell (2005) points out that paid overtime is when extra hours are remunerated with extra money. Unpaid overtime 
represents all other cases of extra hours. However, sometimes these 'unpaid' extra hours can result in other benefits such as higher salary packages, the right to more flexible working arrangements or other package arrangements (Campbell 2005).

It is important to highlight that there are two cohorts of employees on construction sites such as this one. Ostermann $(1987,1988)$ identified these groups as comprising two subsystems within a larger system of employment within a workplace. The first is the white-collar salaried subsystem and the second is the industrial sub-system comprising blue-collar workers. The first group, the 40 salaried staff, includes the site manager, engineers, designers and supervisory staff. Regardless of the hours the people within this group work, they are paid a yearly salary. Hence, the overtime performed by these employees is 'unpaid overtime'. In comparison, the 30 wages staff are the tradespeople and those classified as unskilled labour. These employees are paid at an hourly rate covered in an enterprise bargaining agreement. By working more hours, these employees are paid penalty rates that substantially increase their pay packets, in some cases by up to 60 percent - therefore, 'paid overtime'. Certainly, neither group is homogeneous, but there are direct conflicting motivations for establishing working time arrangements that contribute positively to the work-life balance of both groups of employees.

The time demands of long hours or unsocial work for salaried staff will not be translated into higher salary, although possibly better career or job prospects. A formalised reduction in working hours would mean no reduction in pay, yet potentially, an improvement in the salaried employees' perceptions of their WLB. For those blue-collar workers in the industrial subsystem, other types of satisfaction may be more important due to the differential salary outcomes for working long hours. These waged employees may prefer fewer hours, but the motivation of longer hours 
and increased income is often important and influential in their decision-making process.

Recently, in an attempt to maintain income for waged employees while providing greater time away from the worksite, some projects have experimented with the introduction of a compressed working week. Employees will work longer hours each day over a five-day week, thus eliminating the need for Saturday work. In such arrangements it is normal to add an extra working hour each day from Monday to Friday to compensate the waged staff for lost income on Saturday (Townsend et al. 2003). Where such initiatives have occurred, employees report a range of improvements in both their work and their non-work lives. For example, greater job satisfaction; decreased levels of stress; lower levels of fatigue; increased satisfaction with work-life balance; better relationships with friends and family and reduced levels of illness (Townsend et al 2003). These results provide some evidence that working time initiatives are linked to more positive work related attitudes and well being in the Australian construction industry. The following section will explain the development of this research project and the data collection method.

\section{Method}

As previously mentioned, this case study was an 'alliance' of public and private sector organisations tasked with designing and building a water treatment plant in an Australian capital city. The project lasted for more than 12 months and employed approximately 60 people at its peak which coincided with the research project timing. The case study research was designed to examine the impact of a working time initiative on the WLB of employees within an alliance project in the major infrastructure sector. The project manager approached the research team in an attempt to explore the reasons behind a failed five-day working week in the 
workplace. Involvement from the researchers was following a change back to an industry standard six day working week. Thus, this paper presents an analysis of employee experiences and perceptions without any opportunity to explore employee preferences prior to the working time change. This case provides an interesting example of a workplace that had developed policies to improve the WLB of employees, however, due to a range of factors explored throughout the discussion, these initiatives could not be sustained. The data for this case study was collected in two rounds using interviews and diary study methods.

Firstly, the researchers undertook sixteen semi-structured interviews throughout the late stages of 2005. In total, six of our interviewees were professional staff (engineers, managers) and ten were blue collar workers, two of these interviewees were women (14 men).

The interviews were semi-structured and focused on developing an understanding of the employee and site managers' views about their WLB and the working time transformation at this worksite. The interviews were followed by a diary study of sixteen additional employees. Each employee kept an electronic diary for one week; the diary study ran for three weeks in total. All sixteen participants in this aspect of data collection were salary staff. The 32 people involved in this study spanned a wide age range (between 22 and 63 years of age) and were both male and female, although the female staff were substantially fewer in number (4 of the 32). Seven of the 32 participants did not have children.

The diary study required employees to orally record their thoughts on a personal digital assistant (PDA) at three times each day; 8am; 1pm; and 8pm. Employees were asked to explain at 8am what their expectations for their day were primarily concentrating on working hours and WLB. At 1pm the employees were 
asked to describe whether the expectations of the morning were still current or had there been changes. Finally, at 8pm the employees were asked to describe the way the day 'actually' evolved for them. The employees were encouraged to describe the hours of work and the opportunities to 'think about' and be engaged in non-work activities as a means to determine the employee's perceptions of their WLB.

Data were transcribed verbatim and coded using NVivo. The coding was an iterative process performed by two of the researchers allowing for more nuanced recoding as themes developed throughout the interviews and diary transcripts. Analysis of the data involved thematic coding to discover the strong themes related to aspects of our themes, for example, work-life balance, working hours, fatigue, health and safety, and commitment to the organisation/project.

This paper will now shift attention to exploring the five-day working week at this case study. In addition, we will provide an explanation of why the working time experiment was not completely embraced and consequently demonstrates of the complexities of working time arrangements.

\section{The problems maintaining a five-day working week}

The manager's motivations for a five-day working week were quite simple to reduce the working hours and allow employees a greater opportunity for increased involvement in non-work activities. The employees would continue to work ten hours a day from Monday to Friday and not work at all on Saturdays. Hence, the waged employees would lose the premium Saturday penalty rates which were 'time and a half' for the first 4 hours and 'double time' for the remaining hours worked on Saturdays. However, this site was operating throughout winter, hence daylight hours were fewer and employees were unable to be compensated adequately during the week for lost Saturday hours. Consequently, many wage employees were dissatisfied 
with the five-day working week based purely on financial decisions. When another construction site opened in the area, the alliance lost approximately one-third of their waged workforce. The perspective of some supervisory staff was that some employees who did not leave (and some of those recruited to compensate for losses) were of a lower standard (Interview C1). Again, supervisors assert that the flow-on effect of fewer experienced/skilled workers meant that the project fell behind scheduled targets (Interview L4). This result led to the management group reverting back to the industry standard six-day working week.

The project management group reassessed the reduced working time initiative. The members of the management group always viewed themselves as providing 'flexibility' when employees requested short term leave for medical appointments, family commitments and the like. So while maintaining this 'flexible as required' approach, a roster system was implemented for the salaried staff. This solution meant that while (some) waged staff and project requirements demanded the return of a sixday working week, the salaried staff would not be required to attend every Saturday but one Saturday in four. It is important to note that the six-day working week was not compulsory for waged staff; however, with the financial incentive of six hours at double-time rates of pay, many elected to work Saturdays. As one of the employees suggested when asked why he worked six days a week he explained the primary reason was the increased income (Interview 7). We focus now on providing an analysis of the perceptions employees held of the reduced working time initiative in this worksite.

When the management group decided that discontent from waged employees meant they could no longer sustain a five-day working week on this project, they were required to balance a range of interests. Waged employees who were happy to work 
five days, more or less accepted that they were just reverting back to the industry standard working week. Those employees who were motivated by money rather than time were pleased with the change. However, the salaried staff would receive no WLB benefits and felt that there were distinct and measurable negative impacts from the shift back to the six-day week. We discuss the views of the wages staff and the salaried employees about the impact of their working time change separately below.

\section{Waged Employees}

There are mixed responses from waged workers when it comes to their working time arrangements. However, all waged workers recognise that not working on Saturdays provides them with substantial benefits. These include mental and physical recovery and time to spend with their family or other non-work commitments. Most of the waged employees would prefer a compressed working week. That way, the workers could maintain a five-day working week and the benefits that are associated with it, but they can also maintain the wage levels due to overtime penalty rates. With these competing pressures, waged employees present a pragmatic approach to their working time expectations. Many just accept that they work in a 'six-day industry' and 'you have to take what you can get'. However, there is also an appreciation that in this particular worksite they have a range of beneficial flexibilities. For example, the waged staff were not required to work Saturdays if they preferred to work a five-day week. Waged workers stated:

I work five days. When I first started I said I would only work five days a week...I have worked in here quite a number of Saturdays but I don't work all day. I just come in and do what needs to be done and go home. (Interview 2)

They don't ask me to come in Saturdays, because they know its hard (due to non-work commitments). I have come in a few Saturdays, if they come unstuck, or if they need me specifically for something, like I'll do it, other than that I won't do it. (Interview 9) 


\section{Salaried Employees}

The salaried employees are affected more substantially by WLB initiatives in this workplace. Many salaried staff speak of the benefits that the five-day working week and flexible arrangements provided for them and their families. For example:

(the five-day week)...gave my three kids a chance to do sport. My wife could only take two of them to sport, (so one child) always missed out... This job here is a lot better (than previous six-day jobs). (Interview L4)

The importance of a five-day week in being able to spend time with children and family on Saturday remains an important feature of some employee's working time preferences.

... if you wake up fresh on a Saturday, you go out and do stuff with the kids and all that. And then it's like you do all the stuff with the kids in the morning and then at the end of the day, they're buggered and you're buggered at the end of the day, but you spend more time with your family of course. (Interview 8)

When the worksite reverted to a six-day site, the salaried staff were provided with a roster to ensure that there was adequate site supervision, but also so that employees enjoyed a reduced level of working time in an attempt to promote higher levels of

WLB. Comments relating to the role of the roster in promoting a balance include:

The Saturdays that you do get (off work), you appreciate them, but you do feel a lot more refreshed coming Monday, that extra day makes a big difference. (Interview $\mathrm{C} 1$ )

A salaried staff member who comes to work every second Saturday, states:

(the five-day week) ..it makes you feel better inside, because you are thinking "I've got the Saturday off" and you think "Oh great" and it makes you do your job better, you feel more comfortable, and you're happier doing what you're doing. Makes a difference. (Interview L4)

Employees within this worksite report working upward of ten hours a day, sometimes more than 12 hours a day. This equates to a very long working week that can be 
taxing on employees and on their families and relationships with friends. Employees

from our case study organisation state:

...for blokes like me...really, your life just revolves around the people at work and there's not a lot of social (life). (Interview L4)

Everyone has dreams of what they'd like to do outside of work, but in reality it doesn't happen. (Interview 7)

Most people are divorced...the little time I do have, is always spent with the wife and kids, I've got no other friends. (Interview L4)

My wife complains, she thinks that my job is my wife, my lover, my friend, everything. (Interview 1)

...the guys that you work with, they're more your family than your own family. (Interview 6)

The social cost of these long working arrangements are immense for employees.

Comments include:

(My wife)...brought up the kids... She raised the kids... and when I did come home, she felt like I was interfering with her arrangements. (Interview 3)

When I first started I worked away from home for five years, and I ended up divorced. She'd started to find her interests and like I was just going to work...suddenly, I would come home and yeah, well it was going to be like when I left five years ago, but it wasn't the same. (Interview 6)

The data from our electronic diaries has provided some interesting insights into areas where working time arrangements are altered at short notice with deleterious effect for employees involved. These voice recordings provide valuable insights into the thoughts of employees while they are on the job, and what affects their capacity to maintain a reasonable approach to their working time. The major recurring theme throughout employee comments refers to unexpected interruptions and the effect these interruptions have on the employee's day. These interruptions can range from the weather, to equipment left in the wrong place or not being available when expected, 
batteries on machines being flat, incorrect equipment from suppliers and similar problems. For example:

A couple of unexpected things have cropped up...the rest of the day I will have to spend trying to catch up, but will I (catch up)?

Today is not going as planned. We have to change our priorities...it's like a dog chasing its tail.

... (rain is) going to set us back a bit, not much we can do about it. Just means more work to get done tomorrow.

We have got to move some things that were in the wrong position yesterday, as a result of reading the wrong drawing. We never get everything done that we need to during the day...

What these quotes tell us is that there is a combination of causes that effect a change in daily working hours for employees. Some factors must simply be placed as intrinsic characteristics of the construction industry - rain interruptions, etc. However, things like machines being left on overnight leading to flat batteries for the morning, equipment being delivered to the wrong place on the worksite are simply the result of human error. There is a wealth of literature which discusses the impact fatigue has on decision-making (Dawson and Fletcher, 2003; Dawson et al, 2001). We suggest that with a reduction in working hours, the number of human errors would reduce, having a positive affect on maintaining lower levels of working time for construction staff. In addition, better planning, scheduling and managing problems are also factors that may contribute to reducing these interruptions. While we speculate on these possibilities, this is an important area of investigation for further research. This may be an area that provides managers with information that can be useful in both increasing overall productivity as well as labour output while not increasing work intensity and pressure and at the same time, managing working hours to allow a greater opportunity for developing employee WLB. 
Managers within organisations who make changes for the better should be recognised and acknowledged for their expertise in this area within the construction industry. However, many within this case study concede that it is a change that will be made incrementally, and over a long period of time. We argue that an industry that is having significant difficulties recruiting personnel (according to Considine and Buchanan, 2007, 68 per cent of construction workplaces have had difficulties recruiting personnel in recent times) does not have the time for incremental change.

\section{Discussion and future research}

Some within the construction industry have started to recognise that the benefits of improving work-life balance for employees will have positive outcomes directly back to them through being able to select and retain better employees, improved productivity, and greater overall employee well-being. The industry as a whole is a long way behind many other sectors in this regard, and so attempting interventions like this working time change is one means of dragging the industry forward at a much faster pace.

Many of the employees recognise benefits to the alliance from the effective promotion of reduced working time. It is recognised within the Australian construction industry that Saturday work often has a range of problems that affect productivity, for example, a shorter working day, fewer employees in attendance, and tired employees. In addition, Saturday work is attracting a premium wage through 'time and a half' and 'double time' penalty rates. The problem for project managers is, therefore, maintaining at least the total level of worker output (and increasing overall levels of productivity) while maintaining the wage levels for the employees concerned. 
Management in this worksite remained committed to reducing working hours and encouraging a WLB for their employees, however, a range of factors affected the success of these WLB initiatives and limited their effectiveness. For instance, the structural factors within the industry mean that even within a collaborative alliance, the client-driven expectations of delivery of the completed project within and acceptable cost and timeframe is inconsistent with providing employees with fewer working hours, particularly in times of skills shortages and tight labour markets. Simply put, the demands from the upper levels of organisations to maintain a competitive business, reward shareholders (and stakeholders), and client driven pressures for completion, place significant pressures on site managers and employees to work harder and longer. Individual decision-making does not escape without consideration. When employees can earn up to 60 per cent more than their basic wage for working long hours, there is a clear motivation for working longer hours.

While we do not explore issues of health and safety directly here, working hours and overtime has a direct impact on construction industry safety (Goldenhar et al 2003). Generally, it is suggested that safety performance is better when employees have a two-day break on the weekends (Brown et al, 2010). In future case studies, it would be beneficial to compare measures of health and safety factors. It is possible, for example that adequate rest and recovery time will yield improved worker health and reductions in human error.

At the workplace level there are also significant impediments to developing successful working time interventions to assist employees find greater balance between their work and non-work lives. For instance, with a history and culture of long working hours, many within the workplace and indeed, many managerial staff seem resigned to accept the six-day working week as the norm. The cyclical nature of 
the industry's work patterns through economic and weather patterns means employees rightly want and deserve to have a financial buffer. Hence, when problems arise with reduced time initiatives it is 'easier' to revert to the typical long hours culture. In addition, as our diary study indicates the 'unexpected' problems or planning inadequacies lead to working hours increasing on a day-to-day basis and the employees finding themselves constantly under pressure to 'catch up'. Finally, one of the greatest complexities in cases such as this one is the two distinct cohorts of employees. The wages employees who are rewarded for long hours and the salary earning staff members who are not rewarded on an hours worked basis are reliant upon each other to complete their tasks. However, there is an obvious and centrally important distinction between the working time changes that employees desire and the motivations for these changes.

\section{Conclusion}

This paper has presented a working time case study from the Australian construction industry. This research demonstrates how difficult it can be for managers within organisations to manage working time initiatives which allow employees balance their work and non-work lives. However, what the case also demonstrates is how important it is to employees that their managers engage in alternate rostering arrangements to allow some level of flexibility with working time. This flexibility and alternative rostering arrangements can lead to employees have greater opportunities to balance the complexities of their work and non-work lives.

By industry standards, a 'radical' attempt to move to a standard five day week failed and a more individualised approach to managing working time was introduced. The differing views of the employees were presented showing that waged employees appreciated the notion of the five-day working week, but the financial benefits of 
working Saturdays made their decisions more difficult. The salaried staff were appreciative of the five-day week and indeed, having a five-day week then losing it helped the salaried staff appreciate their weekends when they were rostered off.

A range of factors affected the success and effectiveness of the reduced working time arrangement. Regardless, management in this worksite remained committed to encouraging a better WLB for their employees. Within a liberal-market economy, there will always be some external constraints on what a particular organisation can, or is willing to implement. Yet as the managers in this case demonstrated, even in industries where it is believed to be very difficult to make many improvements, there are initiatives which can be implemented and tested. While this case does not represent an overwhelming success in reducing working time and increasing work-life balance for construction industry workers, it does add to a growing body of research that demonstrates the problems with industry norms and highlights the need for radical reform of structural and workplace policies and approaches. If these considerations are not included in project planning and enterprise bargaining stages of engagement it is unlikely that change will be anything more than incremental, inadequate and ineffective.

\section{References:}

Allen, T, Herst, D, Bruck, C \& Sutton, M (2000) 'Consequences Associated with Work-to-family Conflict: A Review and Agenda for Future Research' Journal of Occupational Health Psychology, 5.

Arthur, M (2003) 'Share Price Reactions to Work-family Initiatives: An Institutional Perspective' Academy of Management Journal, 46 pp. 497-505. 
Bluestone, B and Rose, S (1998) 'The unmeasured labour force: the growth in work hours' Jerome Levy Economics Institute of Bard College, Public Policy Brief No 39.

Boyar, S, Maertz, C, Pearson, A \& Keogh, S (2003) 'Work-family Conflict: A Model of Linkages between Work and Family Domain Variables and Turnover Intentions' Journal of Management Issues, 15 (2).

Brett, J \& Stroh, L (2003) 'Working 61 plus hours a week: Why do Managers do it?' Journal of Applied Psychology, 88 (1) pp. 67-78.

Brown, K., Ling, S., Bradley, L., Lingard, H., and Townsend, K., 'Labouring for Leisure? Achieving Work-life Balance through Compressed Working Weeks', Annals of Leisure Research, forthcoming.

Campbell, I (2002) 'Extended Working Hours in Australia' Labour and Industry, 13 (1) pp. 91-110.

Campbell, I (2005) 'Long Working Hours in Australia: Working Time Regulations and Employer Pressures' Centre for Applied Social Research Working Paper Series, Number 2005-2, Royal Melbourne Institute of Technology, Melbourne. Casper, W \& Buffardi, L (2004) 'Work-life Benefits and Job Pursuit Intentions: The Role of Anticipated Organisational Support' Journal of Vocational Behavior, 65 pp. 391-410.

Clark, S (2001) 'Work Cultures and Work/Family Balance' Journal of Vocational Behaviour, 58 (3) pp. 348-365.

Considine, J and Buchanan, J (2007) 'Workplace IR on the Eve of WorkChoices' Presentation to the National Industrial Relations Conference, Brisbane, 11 September. 
Dawson, D, McCulloch, K \& Baker, A (2001) Extended Working Hours in Australia-Counting the Costs, The Centre for Sleep Research, The University of South Australia, Adelaide.

Dawson, D. \& Fletcher, A. (2001). A quantitative model of work-related fatigue: Background and definition. Ergonomics, 44(2): 144-163.

Francis, V (2003) 'Civil Engineers and Work-family Conflict: The Role of Workplace Support on Their Work and Non-work Satisfaction and Well-being'. Proceedings of the Second International Conference on Construction in the 21st Century (CITC-II) Sustainability and Innovation in Management and Technology, 10-12 December, 2003, Hong Kong.

Goldenhar, L, Hecker, S, Moir, S., \& Rosecrance, J, (2003) 'The “Goldilocks Model” of Overtime in Construction: not too much, not too little, but just right', Journal of Safety Research, 34, pp 215-226.

Greenhaus, J, Collins, K \& Shaw, D (2003) 'The Relation Between Work-family Balance and Quality of Life' Journal of Vocational behaviour, 63 (3) pp. 510531.

Grover, S L \& Crooker, K L (1995) 'Who Appreciates Family-Responsive Human Resource Policies? The Impact of Family-friendly Policies on the Organisational Attachment of Parents and Non-parents' Personnel Psychology, 48 pp. 271-288.

Jacobs, J \& Gerson, K (2000) 'Who are the Overworked Americans?' in L Golden \& D Figart (eds) Working Time: International Trends, Theory and Policy Perspectives, Routledge, London.

Kodz, J., S. Davis, D. Lain, E. Sheppard, J. Rick, M. Strebler, P. Bates, J. Cummings, N. Meager, D. Anxo, S. Gineste and R. Trinczek (2003) 'Working long hours 
in the UK: A review of the research literature, analysis of survey data and cross-national organizational case studies'. London: Department of Trade \& Industry.

Konrad, A M \& Mangel, R (2000) 'The Impact of Work-life Programs on Firm Productivity' Strategic Management Journal, 21 pp. 1225-1237.

Lingard, H \& Francis, V (2004) 'The Work-life Experiences of Office and Site-based Employees in the Australian Construction Industry' Construction Management and Economics, 22 pp. 991-1002.

Lingard H \& Rowlinson S (1994) Construction Site Safety in Hong Kong, Construction Management and Economics 12(6): 501-510.

Madsen, S R (2003) 'The Effects of Home-based Teleworking on Work-family Conflict' Human Resource Development Quarterly, 14 (1).

Chang, A. and McDonald, P. and Burton, P. (2009) "Methodological choices in worklife balance research 1987 to 2006 : a critical review" International Journal of Human Resource Management. (In Press)

Morehead, A, Steele, M, Alexander, M, Stephen, K \& Duffin, L (1997) Changes at Work: The 1995 Australian Workplace Industrial Relations Survey, Longman, Sydney.

Netemeyer, R, Boles, J \& McMurrian, R (1996) 'Development and Validation of Work-Family Conflict and Family-Work Conflict Scales' Journal of Applied Psychology, 81 (4) pp. 400-410.

Osterman, P (1987) Choice of Employment Systems in Internal Labor Markets, Industrial Relations 27(1): 46-47.

Osterman, P. (1988) Employment Futures, Reorganization, Dislocation and Public Policy New York; Oxford University Press. 
Peetz, D, Townsend, K, Russell, B, Houghton, C, Fox, A \& Allan, C (2003) 'Race Against Time: Extended Hours in Australia' Australian Bulletin of Labour, 29 (2) pp. 126-142.

Pocock, B (2001) The Effect of Long Hours on Family and Community Life, Queensland Department of Industrial Relations, Brisbane.

Pocock, B (2003) The Work/Life Collision, The Federation Press, Sydney.

Pocock, B \& Clarke, J (2005) ‘Time, Money and Job Spillover: How Parents' Jobs Affect Young People' Journal of Industrial Relations, 47 (1) pp. 62-76.

Seigwarth Meyer, C, Mukerjee, S \& Sestero, A (2001) 'Work-Family Benefits: Which Ones Maximise Profits' Journal of Managerial Issues, 13 (1) pp. 2844.

Shepanski, P. \& M. Diamond (2007) 'An Unexpected Tragedy: Evidence for the connection between working patterns and family breakdown in Australia'. Sydney: Relationships Forum Australia.

Tausig, M \& Fenwick, R (2001) 'Unbinding Time: Alternative Work Schedules and Work-life Balance' Journal of Family and Economic Issues, 22 pp. 101-119. Townsend, K, Russell, B, Peetz, D, Houghton, C, Fox, A \& Allan, C (2003) Working Time Transformations and Effects, Griffith Work Time Project, Department of Industrial Relations, Griffith University, Brisbane.

Van Rijswsijk, K, Rutte, C G, Bekker, M H J \& Croon, M A (2004) 'The Relationship Among Part-time Work, Work-family Interference and Wellbeing' Journal of Occupational Health Psychology, 9 pp. 286-295.

Van Wanrooy, B., (2007) 'A Desire for 9 to 5: Australians' preference for a standard working week', Labour \& Industry, 17, 3, 71-95 
Warren, J A \& Johnson, P J (1995) 'The Impact of Workplace Support on Workfamily Role Strain’ Family Relations, 44 pp. 163-169.

Watson, I., Buchanan, J., Campbell, I., and Briggs, C., (2003) Fragmented Futures: New Challenges in Working Life, The Federation Press, Sydney.

Wharton, A. S. \& Blair-Loy, M., (2006), Long work hours and family life: A crossnational study of employees' concerns, Journal of Family Issues, 27, 415-436. 